\title{
Thermally-induced phase transformations in KNNS-BNKZ lead-free piezoceramics
}

DOI:

10.1016/j.jeurceramsoc.2019.10.009

\section{Document Version}

Accepted author manuscript

Link to publication record in Manchester Research Explorer

\section{Citation for published version (APA):}

Tangsritrakul, J., Tang, C. C., Hall, D. A., \& Day, S. J. (2019). Thermally-induced phase transformations in KNNSBNKZ lead-free piezoceramics. Journal of the European Ceramic Society.

https://doi.org/10.1016/j.jeurceramsoc.2019.10.009

\section{Published in:}

Journal of the European Ceramic Society

\section{Citing this paper}

Please note that where the full-text provided on Manchester Research Explorer is the Author Accepted Manuscript or Proof version this may differ from the final Published version. If citing, it is advised that you check and use the publisher's definitive version.

\section{General rights}

Copyright and moral rights for the publications made accessible in the Research Explorer are retained by the authors and/or other copyright owners and it is a condition of accessing publications that users recognise and abide by the legal requirements associated with these rights.

\section{Takedown policy}

If you believe that this document breaches copyright please refer to the University of Manchester's Takedown Procedures [http://man.ac.uk/04Y6Bo] or contact uml.scholarlycommunications@manchester.ac.uk providing relevant details, so we can investigate your claim.

\section{OPEN ACCESS}




\section{Thermally-induced phase transformations in KNNS-BNKZ}

\section{2 lead-free piezoceramics}

3 J. Tangsritrakul ${ }^{1,2}$, C.C. Tang ${ }^{3}$, S.J. Day ${ }^{3}$ and D. A. Hall ${ }^{1}$

$4{ }^{1}$ School of Materials, University of Manchester, Manchester M13 9PL, UK.

$5 \quad{ }^{2}$ Faculty of Science and Technology, Thammasat University, Pathum Thani 12120, Thailand

$6 \quad{ }^{3}$ Diamond Light Source, Harwell Science and Innovation Campus, Didcot, Oxfordshire OX11 $7 \quad O D E, U K$

\section{Abstract}

Promising piezoelectric properties have been reported in potassium sodium niobate-based

11 ceramics by introducing $\mathrm{Bi}_{0.5}\left(\mathrm{Na}_{0.82} \mathrm{~K}_{0.18}\right)_{0.5} \mathrm{ZrO}_{3}$ (BNKZ) into $\mathrm{K}_{0.48} \mathrm{Na}_{0.52} \mathrm{Nb}_{0.95} \mathrm{Sb}_{0.05} \mathrm{O}_{3}$ (KNNS) solid

12 solutions in order to control the polymorphic phase transformation temperatures. In the present study, synchrotron $x$-ray powder diffraction (SXPD) was employed in combination with dielectric and ferroelectric measurements in order to clarify the influence of BNKZ on the phase transition temperatures of (1-x)KNNS-( $\mathrm{x})$ BNKZ ceramics (with $\mathrm{x}=0$ to 0.05 ). The results, presented in terms of temperature-dependent SXPD patterns, dielectric permittivity and thermal depolarisation characteristics, confirmed that polymorphic phase transformation temperatures all shifted in a systematic manner with increasing BNKZ content. Broadening of the phase transition regions was also observed with increasing BNKZ content, leading to improvements in thermal stability of the ferroelectric properties. Microstructural examination of the KNNS-BNKZ ceramics revealed the presence of core-shell microstructures; this was correlated with the presence of weak shoulders on the diffraction peaks. 
1 Keywords: polymorphic phase transformation; synchrotron $x$-ray diffraction; core-shell

2 microstructure; potassium sodium niobate; temperature dependence.

3

\section{Introduction}

Piezoelectric materials have been used in a wide range of applications such as medical ultrasonic imaging, piezoelectric printheads and automotive fuel injectors.[1] Lead zirconate titanate (PZT) ceramics are the common piezoelectric materials in commercial products since the near-vertical morphotopic phase boundary (MPB) between ferroelectric rhombohedral and tetragonal (R-T) phases leads to excellent piezoelectric properties combined with good temperature stability.[2,3] However, the major drawback of PZT is the presence of $\mathrm{Pb}$, which causes health and environmental concerns.[1, 4] Therefore, one of the current active topics in piezoelectric materials research is the search for new lead-free materials that could be suitable as replacements for PZT in practical devices.

Presently, several different types of lead-free perovskite solid solutions and complex perovskite compounds have been investigated, including $(\mathrm{Ba}, \mathrm{Ca})(\mathrm{Zr}, \mathrm{Ti}) \mathrm{O}_{3}(\mathrm{BCZT}),(\mathrm{Na}, \mathrm{Bi}) \mathrm{TiO}_{3}(\mathrm{NBT})$ and $(\mathrm{K}, \mathrm{Na}) \mathrm{NbO}_{3}(\mathrm{KNN}) \cdot[1,2,5,6,7]$ Methods for improving the piezoelectric properties of such materials by controlling phase coexistence have also been studied; two common approaches involve compositional control of MPBs or polymorphic phase transformations (PPTs), often leading to the coexistence of different crystalline phases. [1, 8, 9] Lidjici [10] reported the coexistence of R-T phases in the binary system (1-x) $\mathrm{Bi}_{0.5} \mathrm{Na}_{0.5} \mathrm{TiO}_{3}-(\mathrm{x}) \mathrm{BaTiO}_{3}$ (BNT-BT), yielding piezoelectric coefficients $\mathrm{d}_{33}=150$ $p C \mathrm{~N}^{-1}$ and $\mathrm{k}_{\mathrm{t}}=51 \%$ for the composition with $\mathrm{x}=0.065$. An MPB region was also observed in (1x) $\mathrm{Bi}_{0.5} \mathrm{Na}_{0.5} \mathrm{TiO}_{3}-(\mathrm{x}) \mathrm{Bi}_{0.5} \mathrm{~K}_{0.5} \mathrm{TiO}_{3}$ (NBT-KBT) ceramics for $\mathrm{x}=0.16$ to 0.20 , which exhibited the maximum piezoelectric properties in this region. $[11,12,13]$ Furthermore, the occurrence of MPBs in numerous binary and ternary lead-free piezoelectric systems has been reported in many other publications.[14, $15,16,17,18,19,20]$

For KNN-based ceramics, compositional modifications have been employed as a means to shift the phase transformation temperatures towards room temperature and hence to enhance their 
1 piezoelectric properties. Many studies have investigated the substitution of perovskite compounds

2 such as $\mathrm{BiScO}_{3}, \mathrm{CaTiO}_{3}, \mathrm{LiSbO}_{3}, \mathrm{BaTiO}_{3}$ or $\mathrm{LiNbO}_{3}$ in $\mathrm{KNN}$ in order to reduce the orthorhombic-

3 tetragonal (O-T) phase transitiontemperature, $\mathrm{T}_{\text {O-т. }}[1,9,21,22,23,24,25,26]$ Zang reported that $\mathrm{T}_{\mathrm{O} \text { - }}$

4 T for the $0.948\left(\mathrm{~K}_{0.5} \mathrm{Na}_{0.5}\right) \mathrm{NbO}_{3}-0.052 \mathrm{LiSbO}_{3}$ solid solution occurred at $\sim 35^{\circ} \mathrm{C}$ and led to a $\mathrm{d}_{33}$ value

$5 \sim 265 \mathrm{pC} \mathrm{N}^{-1}$.[24] Similarly, improvements in piezoelectric properties were also obtained by the

6 addition of $(x) \mathrm{Ba}\left(\mathrm{Ti}_{0.95} \mathrm{Zr}_{0.05}\right) \mathrm{O}_{3}$ to $(1-\mathrm{x})\left(\mathrm{K}_{0.5} \mathrm{Na}_{0.5}\right) \mathrm{NbO}_{3}$ ceramic $(0.04 \leq \mathrm{x} \leq 0.06)$, attributed to the

7 occurrence of mixed O-T phases at room temperature.[21] Moreover, the coexistence of

8 rhombohedral-tetragonal (R-T) at room temperature was also achieved by doping $\mathrm{Sb}^{5+}$ into

$90.96\left[\left(\mathrm{~K}_{0.48} \mathrm{Na}_{0.52}\right)_{0.95} \mathrm{Li}_{0.05} \mathrm{NbO}_{3}\right]-0.04\left[\mathrm{BaZrO}_{3}\right]$ ceramic or $\mathrm{KNLN}_{1-\mathrm{x}} \mathrm{S}_{\mathrm{x}}-\mathrm{BZ}$ which lead to the shifting of $\mathrm{T}_{\text {O-T }}$

10 and $T_{R-O}$ towards to room temperature. [27] As a result, the enhancement of piezoelectric properties

11 was observed where $x \geq 0.07$ due to the presence of $R$-T mixed phases. In addition, Rubio-Marcos et al.

12 [28] showed that both intrinsic (structural distortion) and extrinsic (increase of grain size)

13 contributions play a significant role on the improvement of piezoelectric properties in

$14\left(\mathrm{~K}_{0.44} \mathrm{Na}_{0.52} \mathrm{Li}_{0.04}\right)\left[\left(\mathrm{Nb}_{0.86} \mathrm{Ta}_{0.10} \mathrm{Sb}_{0.04}\right)_{1-x} \mathrm{Zr}_{5 \times / 4}\right] \mathrm{O}_{3}$ ceramic.

15 Although the temperature-stability of functional properties is generally degradedin materials

16 with PPTs, novel modifications of KNN-based ceramics have yielded piezoelectric properties that are

17 said to be comparable to those of PZT.[29] Promising piezoelectric properties in (1-

$18 \mathrm{x}) \mathrm{K}_{0.48} \mathrm{Na}_{0.52} \mathrm{Nb}_{0.95} \mathrm{Sb}_{0.05} \mathrm{O}_{3}-(\mathrm{x}) \mathrm{Bi}_{0.5}\left(\mathrm{Na}_{0.82} \mathrm{~K}_{0.18}\right)_{0.5} \mathrm{ZrO}_{3}$ (KNNS-BNKZ) ceramics are attributed to the

19 coexistence of R-T phases at room temperature. [30] However, the precise nature of phase coexistence

20 in KNNS-BNKZ ceramics and the influence of the polymorphic phase transformations on their

21 temperature-dependent functional properties have yet to be clarified.[30, 31] Therefore, the

22 influence of BNKZ content on the thermal evolution of structure and functional properties of (1-

$23 \mathrm{x})$ KNNS- $(\mathrm{x})$ BNKZ ceramics were investigated in the present study. 


\section{2. Experimental methods}

$3 \mathrm{x})\left(\mathrm{K}_{0.48} \mathrm{Na}_{0.52} \mathrm{Nb}_{0.95} \mathrm{Sb}_{0.05}\right)-(\mathrm{x})\left(\mathrm{Bi}_{0.5}\left(\mathrm{Na}_{0.82} \mathrm{~K}_{0.18}\right)_{0.5} \mathrm{ZrO}_{3}\right)$ ceramics $(0 \leq \mathrm{x} \leq 0.05)$, denoted as OBNKZ to $5 \mathrm{BNKZ}$ in this work. The precursor powders of $\mathrm{K}_{2} \mathrm{CO}_{3}(99.0 \%), \mathrm{Na}_{2} \mathrm{CO}_{3}(99.8 \%), \mathrm{Nb}_{2} \mathrm{O}_{5}(99.0 \%), \mathrm{Sb}_{2} \mathrm{O}_{3}$ (98.0\%), $\mathrm{Bi}_{2} \mathrm{O}_{3}(99.0 \%)$ and $\mathrm{ZrO}_{2}(99.0 \%)$ were milled in isopropanol for 24 hours and then dried in an oven at $85^{\circ} \mathrm{C}$ for 24 hours. Note that $\mathrm{K}_{2} \mathrm{CO}_{3}$ and $\mathrm{Na}_{2} \mathrm{CO}_{3}$ powders were dried overnight before weighing due to their moisture sensitivity.[32] Then, the mixed powders were calcined at $850^{\circ} \mathrm{C}$ for 6 hours followed by milling after calcination for 24 hours. Next, the resulting powders were mixed with $2 w t \%$ polyethylene glycol $(\mathrm{m} . \mathrm{w} .=1500)$ as a lubricant/binder before uniaxial pressing at $25 \mathrm{MPa}$ into a disc shape with diameter of $\sim 8 \mathrm{~mm}$ and thickness of $\sim 1 \mathrm{~mm}$. The green samples, covered by a layer of calcined powder, were sintered in an al umina crucible at temperatures of 1120, 1140, 1150 and 1170 for OBNKZ, 1BNKZ, 2BNKZ to $4 \mathrm{BNKZ}$ and $5 \mathrm{BNKZ}$, respectively, for 3 hours after binder burnout at $500^{\circ} \mathrm{C}$ for 1 hour.

For microstructural studies, the OBNKZ to 5BNKZ ceramics were mounted in acrylic resin.

Then, the cross-sections of all specimens were ground sequentially using silicon carbide papers of grade $\mathrm{P} 400$ to $\mathrm{P} 1200$ and polished with 6, 1, and $0.25 \mu \mathrm{m}$ diamond paste, then finally with $\mathrm{SiO}_{2}$ suspensionfor 1 hour in the final polishing step. Subsequently, the polished samples were coated with carbon prior to observing the microstructure using a field-emission scanning electron microscope (FEGSEM), Philips XL30, in backscattered electron (BSE) imaging mode. Also, micro-chemical analysis was carried out using energy-dispersive $x$-ray spectroscopy (EDS). The average grain size was calculated by the linear intercept method.[33] For electrical measurements, silver electrodes (Gwent Group type C2000107P3) were applied on the parallel surfaces of the samples, ground to $\sim 1 \mathrm{~mm}$ in thickness, and then fired at $550^{\circ} \mathrm{C}$ for 30 min. The temperature-dependent dielectric properties were measured over a range of temperature between $50^{\circ} \mathrm{C}$ and $450^{\circ} \mathrm{C}$ using a HP4284A impedance analyser at a frequency of $100 \mathrm{kHz}$. The ferroelectric P-E hysteresis behaviour was measured as a function of temperature from $25^{\circ} \mathrm{C}$ to $150^{\circ} \mathrm{C}$. 
1 Four cycles of a sinusoidal electric field with amplitude of $4 \mathrm{kV} \mathrm{mm}^{-1}$ and frequency of $2 \mathrm{~Hz}$ were

2 applied to the samples immersed in silicone oil. Further details of the P-E loop measurement system

3 used in this experiment are given in previous work. [34] In addition, the depolarisation temperature

$4 \quad\left(T_{d}\right)$ was investigated by using a HP34401A multimeter in combination with a current amplifier [34] to determine the remnant polarisation of a poled sample as a function of temperature from $25^{\circ} \mathrm{C}$ to $350^{\circ} \mathrm{C}$. Note that all samples were poled prior to measurement by applying an AC field with amplitude of $4 \mathrm{kV} \mathrm{mm}^{-1}$ at room temperature.

Since phase coexistence in (1-x)KNNS-(x)BNKZ ceramics has been reported in the

9 literature[30], an in-situ temperature-dependent high resolution Synchrotron X-ray Powder 10 Diffraction (SXPD) study was carried out on beamline I11 at the Diamond Light Source, UK, with a 11 photon energy of $15 \mathrm{keV}(\lambda=0.825711 \AA$ A $)$, calibrated using NIST SRM640c Si standard).[35] Sample 12 preparation for SXPD measurements involved the packing of crushed ceramic powders into borosilicate glass capillaries of diameter $0.3 \mathrm{~mm}$, which were mounted on a magnetic spinner. The temperature-dependent SXPD patterns were collected by using a wide-angle position sensitive detector(PSD), covering the angular range from $10^{\circ}$ to $90^{\circ} 2 \theta$, in conjunction with a $\mathrm{LN}_{2}$ Cryostream (Oxford Cryosystems) to control the temperature from - 143 to $227^{\circ} \mathrm{C}$ and a Cyberstar hot air blower to provide higher temperatures up to $450^{\circ} \mathrm{C}$. Phase identification at different temperatures was achieved by means of a full-pattern refinement method with a Pseudo-Voigt peak-shape function using Topas software (version 5, Bruker).[36]

\section{Results and Discussion}

\subsection{Microstructure}

Figure 1 shows the polished cross-section microstructures for the KNNS-BNKZ ceramics observed by using SEM in BSE mode. Chemically homogeneousgrains with average size of $3.9 \pm 1.9 \mu \mathrm{m}$ were observed only for the unmodified KNNS, while the addition of BNKZ had a dramatic effect on microstructure. Chemical heterogeneity in the form of core-shell microstructures was evident in all 
1 BNKZ-containing compositions, as shown in Figure 1(b)-(d).[37, 38] For the 1BNKZ composition, there

2 are some ultra-large grainssurrounded by fine grains, causing the average grain size to drop to $1.4 \pm 0.6$

$3 \mu \mathrm{m}$. However, as the BNKZ content increased from 2BNKZ to 4BNKZ, the average grain size increased

4 slightly from $1.8 \pm 0.4 \mu \mathrm{m}$ to $2.6 \pm 0.4 \mu \mathrm{m}$. The increase of grain size with increasing BNKZ content is

5 possibly due to liquid phase formation due to the presence of bismuth oxide, together with the

6 associated eutectic reactions.[39] In contrast, the average grain size of the 5BNKZ composition was

7 significantly lower, at less than $1 \mu \mathrm{m}$. Similarly, Xing [39] al so found a sudden decrease of grain size in

$8 \quad(1-x) \mathrm{K}_{0.48} \mathrm{Na}_{0.52} \mathrm{Nb}_{0.95} \mathrm{Sb}_{0.05} \mathrm{O}_{3}-(\mathrm{x})\left(\mathrm{Bi}_{0.5} \mathrm{Na}_{0.5}\right)_{0.9}\left(\mathrm{Li}_{0.5} \mathrm{Ce}_{0.5}\right)_{0.1} \mathrm{ZrO}_{3}$ ceramics for $\mathrm{x}>0.045$ because the

9 addition of excess $\left(\mathrm{Bi}_{0.5} \mathrm{Na}_{0.5}\right)_{0.9}\left(\mathrm{Li}_{0.5} \mathrm{Ce}_{0.5}\right)_{0.1} \mathrm{ZrO}_{3}$ inhibited grain growth. Although Wang and $\mathrm{Zhen} \mathrm{[40,}$

10 41] found that the occurrence of core-shell microstructure caused a decrease of piezoelectric

11 properties in KNN-based ceramics, there are some contradictory reports of promising piezoelectric

12 properties in core-shell microstructured ceramics for $\mathrm{Bi}_{1 / 2} \mathrm{Na}_{1 / 2} \mathrm{TiO}_{3}-\mathrm{SrTiO}_{3}$ or

$13\left(\mathrm{~K}_{0.51} \mathrm{Na}_{0.47} \mathrm{Li}_{0.02}\right)\left(\mathrm{Nb}_{0.8} \mathrm{Ta}_{0.2}\right) \mathrm{O}_{3}-\mathrm{CaZrO}_{3}$ solid solutions. [38, 42] This suggests that the role of core-shell

14 microstructure on piezoelectric properties is still unclear and requires further investigation to clarify

15 the mechanisms that control functional properties in such materials. 

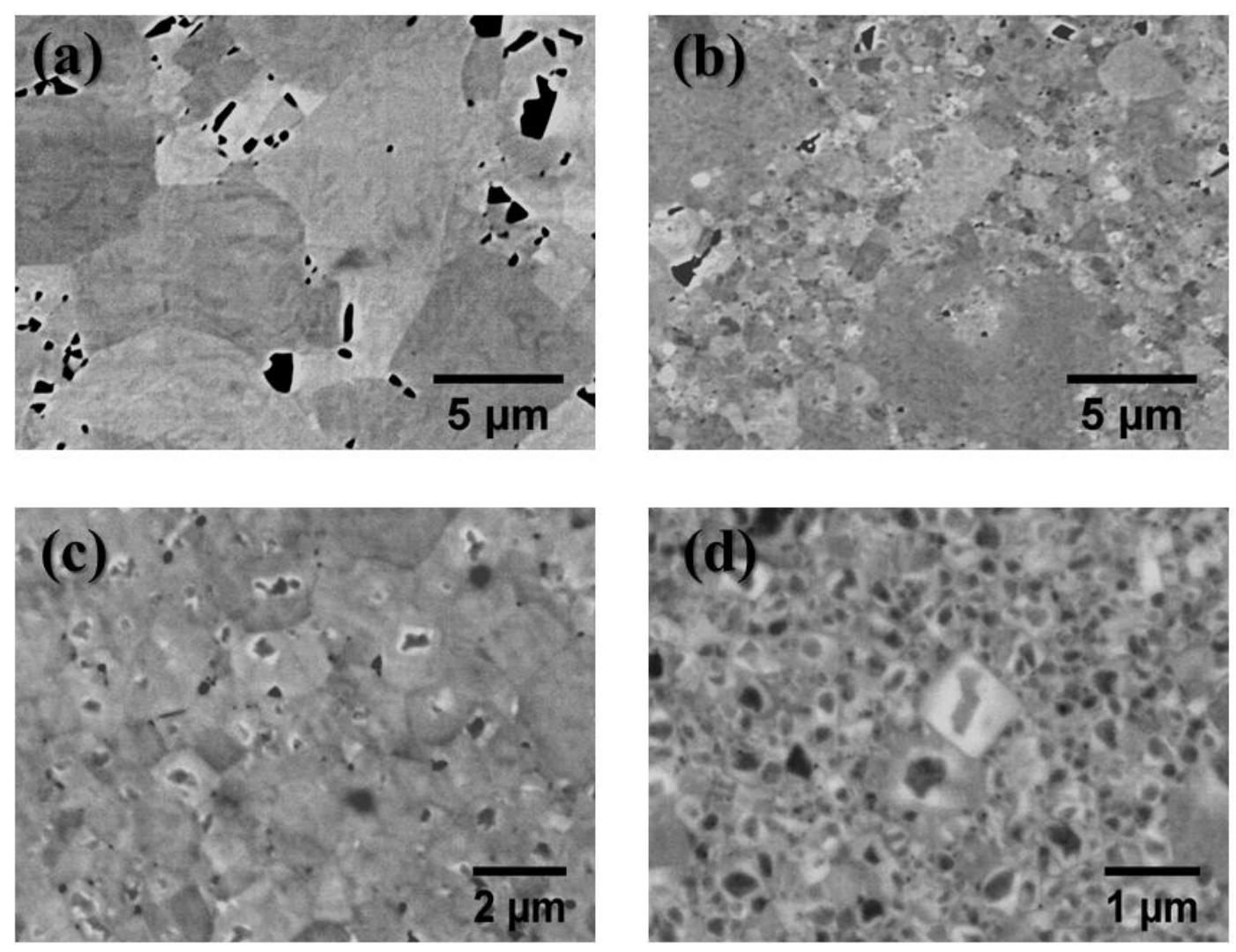

2 Figure 1. Polished cross-sections illustrating SEM images (BSE mode) of (a) OBNKZ with homogeneous microstructure and (b)-(d) 1BNKZ, 3BNKZ and 5BNKZ with chemically heterogeneous core-shell type microstructures.

An investigation of chemical heterogeneity in the core-shell microstructure of the 3BNKZ ceramic was conducted using EDS, as illustrated Figure 2. The results obtained for four different areas

8 in the microstructure, labelled as core, shell, region 1 and region 2, are shown. The EDS results reveal

9 that the amount of $\mathrm{K}$ in the core is slightly higher than that of $\mathrm{Na}$, but lower in the shell, as shown in

10 Figure 2(a). Similarly, Zhou [43] reported the occurrence of $\mathrm{K}^{+}$vacancies in the shell regions for core-

11 shell structured $\left(\mathrm{K}_{0.48(1+\times)} \mathrm{Na}_{0.52}\right)_{0.95} \mathrm{Li}_{0.05} \mathrm{Nb}_{0.95} \mathrm{Sb}_{0.05} \mathrm{O}_{3}$ ceramics. The origin of chemical heterogeneity in

12 KNN-based piezoceramics has been discussed recently by Thong et al. [44] According to the difference

13 of diffusion couple reaction rate between $\mathrm{Na}_{2} \mathrm{CO}_{3} / \mathrm{Nb}_{2} \mathrm{O}_{5}$ and $\mathrm{K}_{2} \mathrm{CO}_{3} / \mathrm{Nb}_{2} \mathrm{O}_{5}$, chemical heterogeneity

14 can originate in the $\mathrm{KNN}$ calcined powder in which $\mathrm{NaNbO}_{3}$ grains can growth larger than those of 
$1 \mathrm{KNbO}_{3}$. Consequently, the A-site chemical heterogeneity occurred in the $\mathrm{KNN}$ sintered ceramic,

2 consistent with the EDS results presented in Figure 2(a). However, for the other elements, no obvious

3 differences in concentrations were observed between core and shell regions. investigated by EDS. The results reveal that region 1 contains high $\mathrm{K}$ and $\mathrm{Nb}$ concentrations, with low amounts of $\mathrm{Na}, \mathrm{Sb}, \mathrm{Bi}$ and $\mathrm{Zr}$, which corresponds to the EDS results of secondary phase in $\mathrm{KNN}^{\mathrm{Z}} \mathrm{ZrO} \mathrm{O}_{2}$ reported by Malic et al.[45] Hence, it can be assumed that region 1 is possibly the secondary phase of $\mathrm{K}_{2.75} \mathrm{Nb}_{5.45} \mathrm{O}_{15}$ that was observed by the high-resolution SXPD as mentioned in previous work. [31] On inside the core-shell grains which could not be detected by diffraction.

(a)

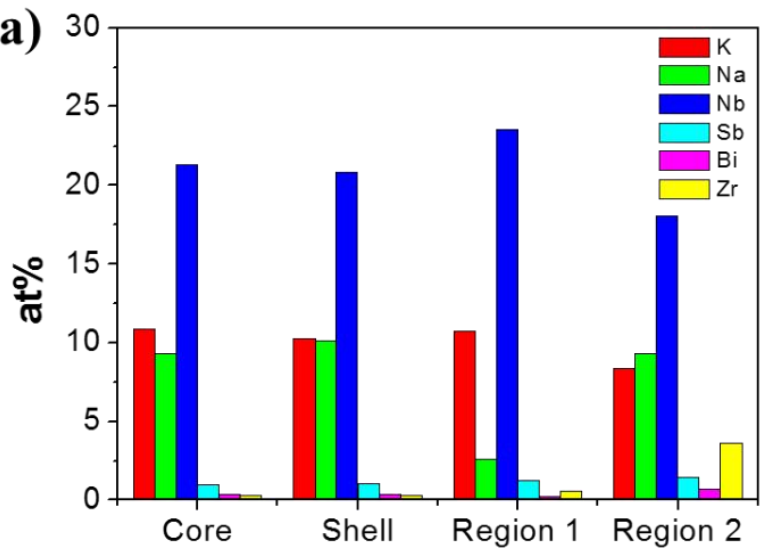

(b)

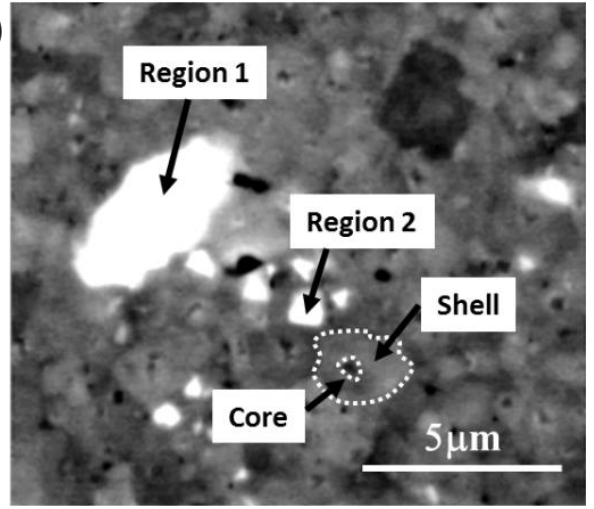

Area

Figure 2. (a) EDS analysis of core, shell, region 1 and region 2 in (b) BSE image for $3 B N K Z$ ceramic showing K-enrichment and $\mathrm{K}$-deficiency in core and shell regions, respectively. In addition, the secondary phase of $K_{2.75} \mathrm{Nb}_{5.45} \mathrm{O}_{15}$ and the segregation of Sb, Biand Zrare identified in regions 1 and 2, respectively.

\subsection{Thermally-induced phase transformations} from $-143^{\circ} \mathrm{C}$ to $227^{\circ} \mathrm{C}$ for the KNNS-BNKZ ceramics are shown in Figure 3; these plots illustrate the 
1 effects of BNKZ on the phase transition temperatures, using the results of high-resolution SXPD

2 measurements. For $\mathrm{BBNKZ}$, two polymorphic phase transformations occur upon heating from $-143^{\circ} \mathrm{C}$

3 to $227^{\circ} \mathrm{C}$; the single peak of the rhombohedral $(R)$ phase is present at $-143^{\circ} \mathrm{C}$, transforming into

4 characteristic doublets associated with orthorhombic $(\mathrm{O})$ and tetragonal $(\mathrm{T})$ phases at temperatures

5 around $-100^{\circ} \mathrm{C}$ and $100^{\circ} \mathrm{C}$, respectively, as shown in Figure $3(\mathrm{a})$.

On introducing BNKZ into the KNNS solid solution, the two polymorphic phase

7 transformations are still observed for the 1BNKZ composition but the transition temperatures differ

8 from those of the unmodified KNNS ceramic. Furthermore, there is a weak shoulder that becomes

9 apparent, especially in the tetragonal phase field, at lower $2 \theta$ values for both $(002)_{\mathrm{T}}$ and $(020)_{\mathrm{T}}$

10 reflections, indicated by the arrows in Figure 3(b). With increasing BNKZ composition, it was found

11 that the orthorhombic phase region disappears for the 3BNKZ composition, while only two phases,

12 tetragonal and rhombohedral, are observed over this range of temperature. It is assumed that $\mathrm{T}_{\mathrm{R}-\mathrm{O}}$

13 and $\mathrm{T}_{\mathrm{O}-\mathrm{T}}$ are shifted with increasing BNKZ content and merge at room temperature. Consequently, the

14 orthorhombic phase region is not apparent for the 3BNKZ ceramic. On the other hand, only broad

15 peaks are present for the 5BNKZ composition over the full temperature range, which is possibly

16 related to its microstructure, which exhibits the smallest grain size of less than $1 \mu \mathrm{m}$, as illustrated in

17 Figure $1(\mathrm{~d})$. 
(a)

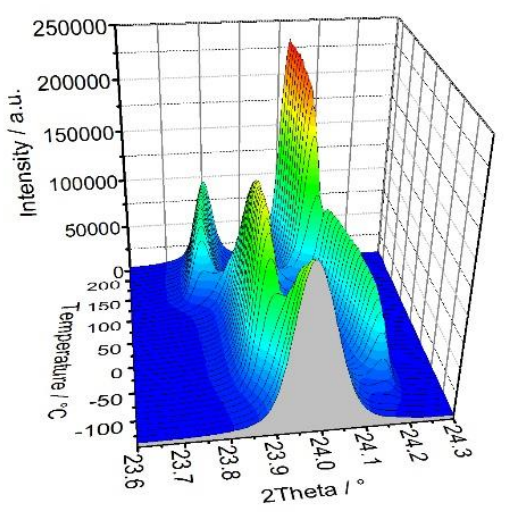

(c)

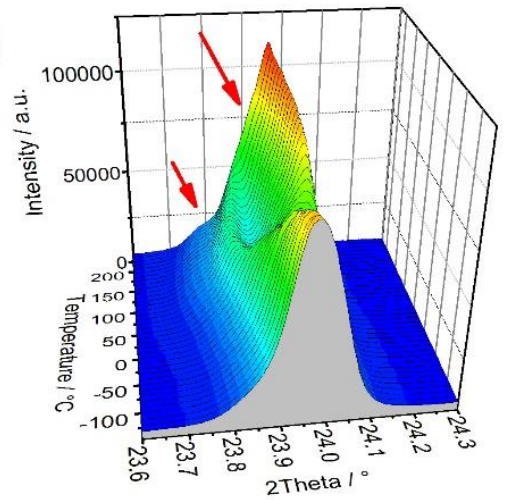

(b)

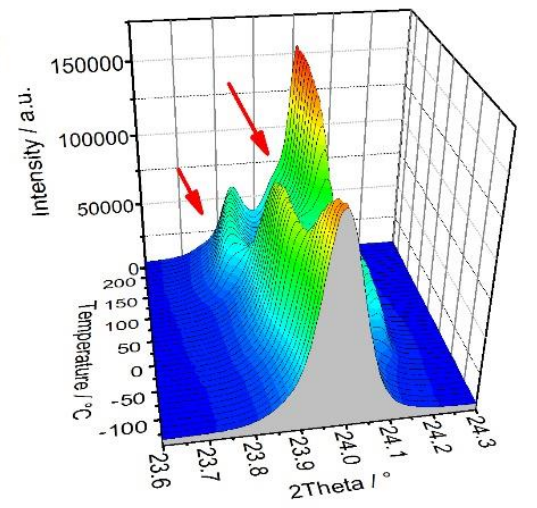

(d)

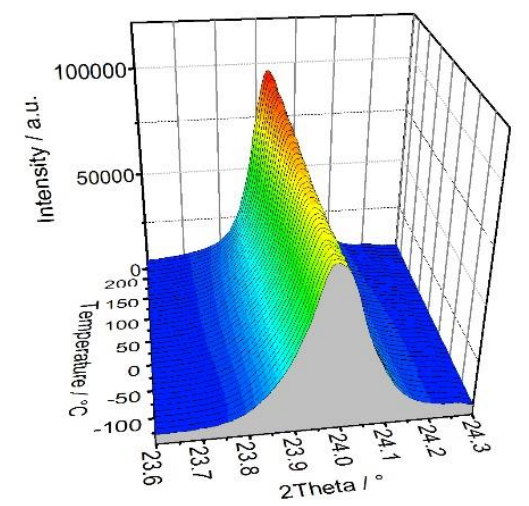

2 Figure 3. Changes in $\{200\}_{p}$ diffractions peak profiles for (a) OBNKZ, (b) $1 B N K Z,(c) 3 B N K Z$ and (d) $5 B N K Z$ ceramics upon heating from $-143^{\circ} \mathrm{C}$ to $227^{\circ} \mathrm{C}$ showing modification of the thermally-induced phase transformations with increasing $B N K Z$ content $(\lambda=0.825711 \AA)$.

In addition, the 2D contour maps of the $\{200\}_{p}$ reflection for all of the KNNS-BNKZ ceramics

7 are illustrated in Figure 4. It is evident that $\mathrm{T}_{\mathrm{O}-\mathrm{T}}$ gradually decreases, while $\mathrm{T}_{\mathrm{R}-\mathrm{O}}$ slightly increases with

8 increasing BNKZ content. As a result, the orthorhombic phase region becomes more contracted and

9 disappears for 3BNKZ, giving rise to the R-T mixed phase region at room temperature, as seen in Figure

$103(c)$ and Figure 4(d). Furthermore, another effect of introducing BNKZ into the KNNS solid solution is

11 the broadening of the mixed phase region near $\mathrm{T}_{\mathrm{R}-\mathrm{O}}$ and $\mathrm{T}_{\mathrm{O}-\mathrm{T}}$ as the BNKZ content increases. Many

12 publications $[30,46]$ have identified the shifting of $\mathrm{T}_{\mathrm{O}-\mathrm{T}}$ and $\mathrm{T}_{\mathrm{R}-\mathrm{O}}$ on the basis of temperaturedependent dielectric permittivity measurements. However, in the present work, the high-resolution 
1 SXPD measurements are used in combination with dielectric studies to confirm the shifting and

2 broadening of $\mathrm{T}_{\mathrm{O}-\mathrm{T}}$ and $\mathrm{T}_{\mathrm{R}-\mathrm{O}}$ directly.
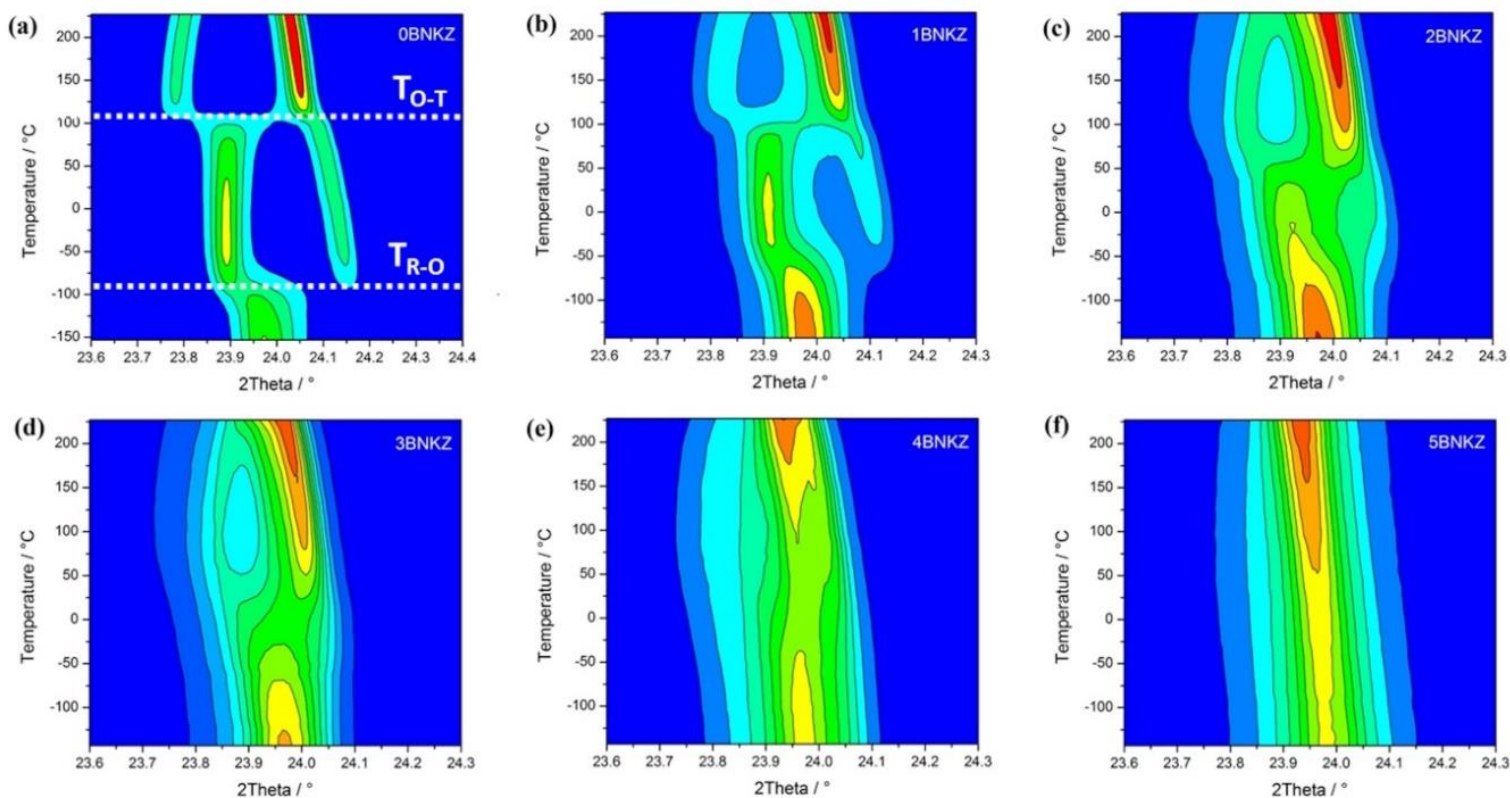

Figure 4. Contour plots of the $\{200\}_{p}$ diffractions peaks on heating from -143 to $227{ }^{\circ} \mathrm{C}$, showing the shifting and broadening of $T_{O-T}$ and $T_{R-O}$ transformation regions for (a)OBNKZ, (b)1BNKZ, (c)2BNKZ,

(d)3BNKZ, (e)4BNKZ and $(f) 5 B N K Z$ ceramics $(\lambda=0.825711 \AA)$.

Some additional high temperature measurements up to $450^{\circ} \mathrm{C}$, in excess of the Curie point

$\left(T_{c}\right)$, were carried out in order to extend the study into the cubic $(C)$ phase field. Figure 5 shows the

$(200)_{C}$ peak profiles together with temperature-dependent lattice parameters for OBNKZ and 2BNKZ compositions at temperatures above $\mathrm{T}_{\mathrm{c}}$, from $300^{\circ} \mathrm{C}$ to $450^{\circ} \mathrm{C}$. Note that the lattice parameters were derived from full-pattern refinement with cubic space group Pm3m. The data presented in Figure 5(a) represents a single cubic phase for the OBNKZ composition, with a gradual increase of the lattice parameter being apparent due to thermal expansion.[38] In contrast, the high temperature SXPD profiles for the 2BNKZ composition reveal the presence of a persistent shoulder inall reflections which indicates the existence of a second cubic phase, as illustrated in Figure 5(b). Correspondingly, this 
1 persistent peak is consistent with the occurrence of the weak shoulders that were also identified in

2 Figure $3(b-c)$.

(a)

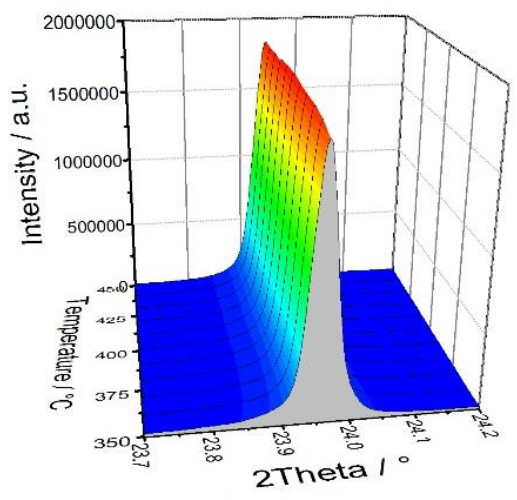

(b)

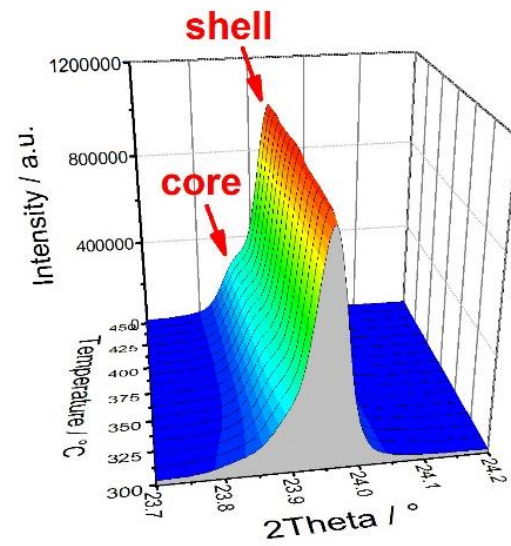

3

4 Figure 5. Surface plots of the (200) ${ }_{c}$ peak profiles (left) with temperature-dependentlattice parameters

(right) within the cubic phase field for (a)OBNKZ and (b)2BNKZ compositions ( $\lambda=0.825711 \AA$ ). The noticeable deviation of the $a_{\text {core }}$ data in $(b)$ is due to the weak intensity contributions of the second cubic phase.

The presence of the weak shoulder at low $2 \theta$ values in the SXPD profiles can be attributed to

10 the occurrence of core-shell microstructures, in which there are variations in chemical composition

11 between core and shell regions; K-rich in the core and K-deficient in the shell, as mentioned earlier in

12 section 3.1. In previous work, Tellier reported that the unit cell size of $\mathrm{K}_{\mathrm{x}} \mathrm{Na}_{1-\mathrm{x}} \mathrm{NbO}_{3}$ ceramics increased

13 with increasing $\mathrm{K}$ content because the effective ionic radius of $\mathrm{K}^{+}(\sim 1.64 \AA)$ is larger than that of $\mathrm{Na}^{+}$

14 ( 1.39 $\AA$ ).[47] Therefore, it can be assumed that the occurrence of the weak shoulder at low $2 \theta$, or 
1 high $d$-spacing, is possibly generated by the cubic phase of the K-rich core. On the other hand, the

2 presence of the major peak is attributed to the cubic reflection of the K-deficient shell. It can be concluded that the observed weak shoulder in Figure $5(b)$ is associated with the core, while the major peak is attributed to the shell.

\subsection{Identification of crystal structure at different temperatures}

Figure 6 shows the $\{200\}_{p}$ profiles from full-pattern refinements for the KNNS-BNKZ ceramics at certain temperatures of $-140^{\circ} \mathrm{C}, 20^{\circ} \mathrm{C}, 227^{\circ} \mathrm{C}$ and $350^{\circ} \mathrm{C}$. It is observed that the best-fit refinements for $\mathrm{OBNKZ}$ at these temperatures are rhombohedral $R 3 m R(\mathrm{R})$, orthorhombic $A m m 2(\mathrm{O})$, tetragonal P4mm (T) and cubic Pm3m (C), respectively. The evolution of lattice parameters and phase fractions as a function of temperature upon heating from $-153^{\circ} \mathrm{C}$ to $227^{\circ} \mathrm{C}$ for the unmodified KNNS ceramic are also illustrated in Figure 8(a) and (c), respectively.
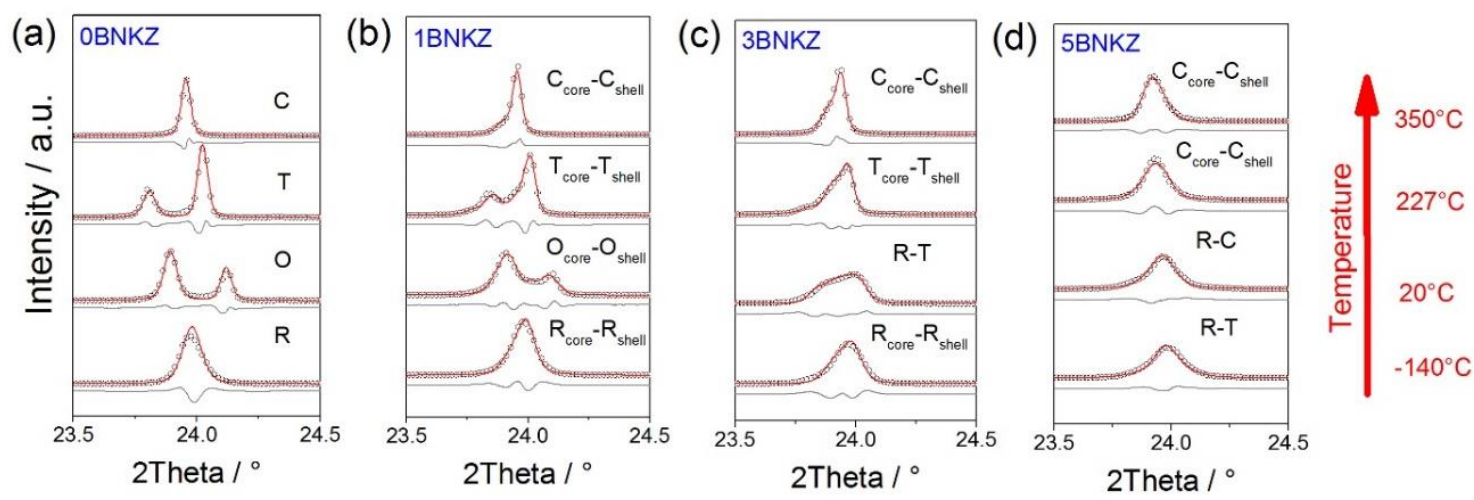

Figure 6. $\{200\}_{p}$ diffraction peak profiles illustrating the measured (black circles), calculated (red line) and difference (grey line) curves from full-pattern refinements at $-140^{\circ} \mathrm{C}, 20^{\circ} \mathrm{C}, 227^{\circ} \mathrm{C}$ and $350^{\circ} \mathrm{C}$ for $0.825711 \AA$ ).

microstructure as well as the weak shoulder in the SXPD profiles, as described previo usly, full-pattern 
1 refinement for the $1 \mathrm{BNKZ}$ composition at $-140^{\circ} \mathrm{C}$ is best fitted with coexisting rhombohedral models,

2 referred to as core-shell rhombohedral. It was found that the lowest $R_{w p}$ from the full-pattern

3 refinement of $1 \mathrm{BNKZ}$ at $-140^{\circ} \mathrm{C}$ with a single rhombohedral model was $7.70 \%$, while the core-shell

4 rhombohedral model shows an improved fit with $R_{w p}$ of $5.57 \%$. Additionally, the improvement of the

5 calculated curve was also evident when fitting with core-shell rhombohedral model, as shown in

6 Figure 7. This implies that the stable phase formation for the $1 B N K Z$ ceramic at $-140^{\circ} \mathrm{C}$ comprises core-

7 shell rhombohedral $\left(\mathrm{R}_{\text {core }}-\mathrm{R}_{\text {shell }}\right)$.

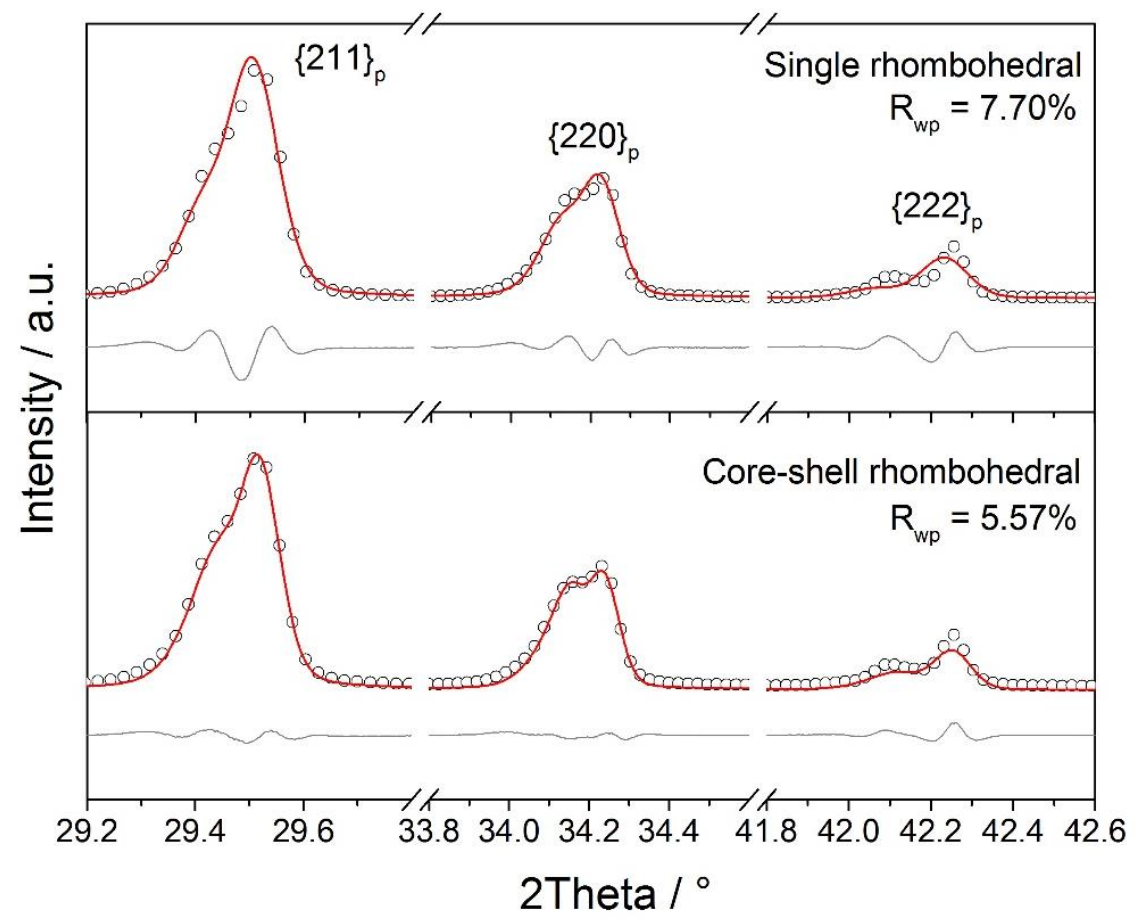

8

9 Figure 7. Comparison of full-pattern refinements for $1 B N K Z$ composition at $-140^{\circ} \mathrm{C}$ with single

rhombohedral and core-shell rhombohedral models showing the improvements of the calculated (red)

and difference (grey) curves in core-shell rhombohedral model $(\lambda=0.825711 \AA)$.

With increasing temperature, it was found that the crystal structure of the $1 \mathrm{BNKZ}$ ceramic

14 transforms to core-shell orthorhombic $\left(\mathrm{O}_{\text {core }}-\mathrm{O}_{\text {shell }}\right)$, core-shell tetragonal $\left(\mathrm{T}_{\text {core }}-\mathrm{T}_{\text {shell }}\right)$ and core-shell

15 cubic $\left(\mathrm{C}_{\text {core }} \mathrm{C}_{\text {shell }}\right)$ at $20^{\circ} \mathrm{C}, 227^{\circ} \mathrm{C}$ and $350^{\circ} \mathrm{C}$, respectively, as observed in Figure $6(\mathrm{~b})$. The evolution of core-shell lattice parameters and phase fractions for the $1 \mathrm{BNKZ}$ ceramic from $-153^{\circ} \mathrm{C}$ to $227^{\circ} \mathrm{C}$ is 
1 illustrated in Figure 8(b) and (d), showing a broader transition temperature region in comparison with

2 OBNKZ. Note that the lattice parameters of each phase in the transition region were extrapolated 3 individually from the trend of each phase in the single phase field.

(a)

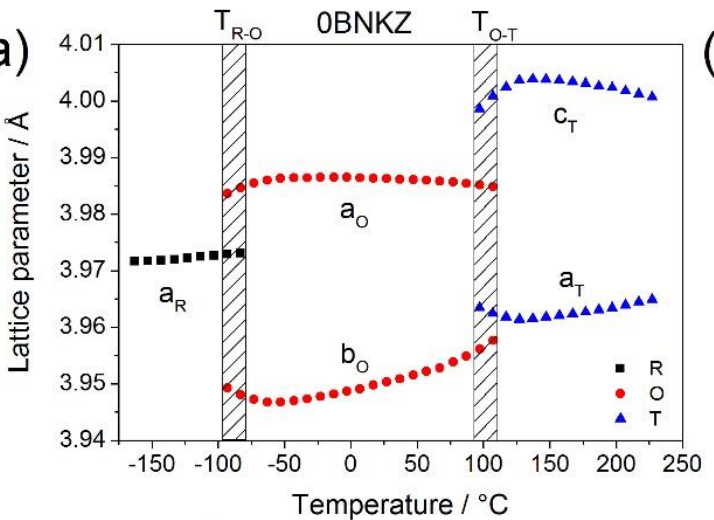

(c)

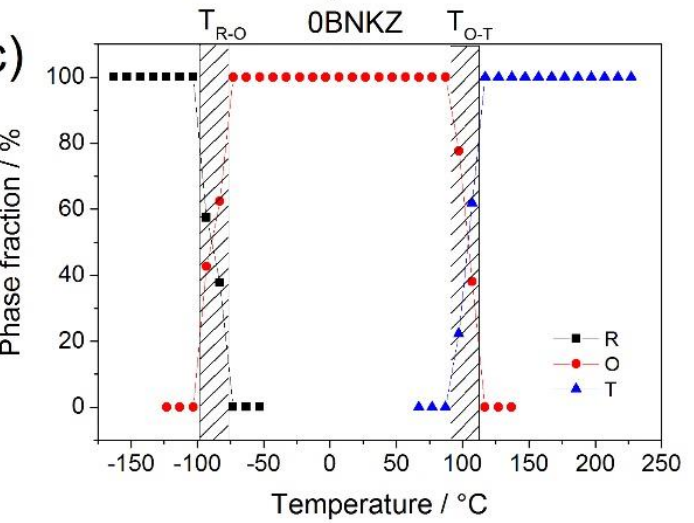

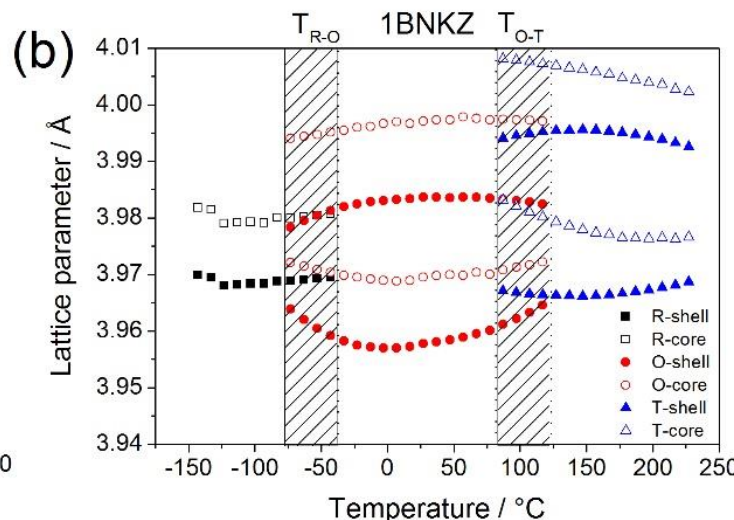

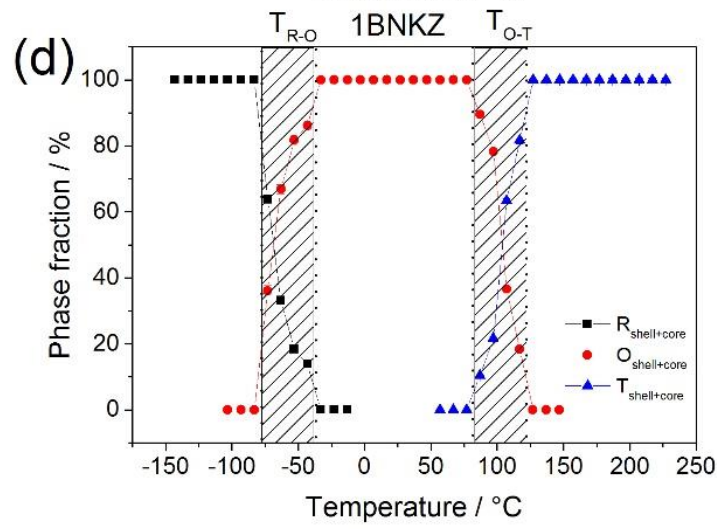

Figure 8. Thermal evolution of (a),(b) lattice parameters and (c),(d) phase fractions of rhombohedral $(R)$, orthorhombic $(O)$ and tetragonal $(T)$ phases for OBNKZ and $1 B N K Z$ compositions showing the widening of the phase transition range. Note that the uncertainties in lattice parameters and phase fractions are typically less than $0.002 \%$ and $1 \%$, respectively.

Although the identification of phase formation at room temperature described in previous work indicated the occurrence of O-T coexisting phases in the 1BNKZ composition [31], the contour plots of the thermally-induced SXPD profiles (Figure 4) in the present results revealed contradictory results. The coexistence of $\mathrm{R}-\mathrm{O}$ was observed clearly in the temperature range of $-73^{\circ} \mathrm{C}$ to $-43^{\circ} \mathrm{C}$, whereas the O-T mixed phase occurred for temperatures between $87^{\circ} \mathrm{C}$ and $117^{\circ} \mathrm{C}$, as seen in the 
1 figure. Hence, phase formation for the $1 \mathrm{BNKZ}$ composition at room temperature $\left(\sim 20^{\circ} \mathrm{C}\right)$ is more

2 correctly assigned to core-shell orthorhombic $\left(\mathrm{O}_{\text {core }}-\mathrm{O}_{\text {shell }}\right)$ instead of coexisting O-T phases. This

3 suggests that the identification of coexisting phases at room temperature is not always straightforward. Therefore, the additional analysis of temperature-dependent diffraction profiles should be considered in order to make more accurate identification of mixed phases at room temperature.

Furthermore, the phase identification for the 3BNKZ ceramic becomes more complicated due to the broadening of the phase transitions with increasing BNKZ content. Figure $6(c)$ shows that the core-shell rhombohedral $\left(R_{\text {core }}-R_{\text {shell }}\right)$ structure is still observed for $3 B N K Z$ at a temperature of $-140^{\circ} \mathrm{C}$, while the coexistence of rhombohedral-tetragonal $(R-T)$, core-shell tetragonal $\left(T_{\text {core }}-T_{\text {shell }}\right)$ and core-

11 shell cubic $\left(C_{\text {core }}-C_{\text {shell }}\right)$ phases are found at temperatures of $20^{\circ} \mathrm{C}, 227^{\circ} \mathrm{C}$ and $350^{\circ} \mathrm{C}$, respectively. Fullpattern refinements of the 5BNKZ data were also attempted, although the SXPD profiles of this composition show diffuse diffraction peaks. It was found that $5 \mathrm{BNKZ}$ at $-140^{\circ} \mathrm{C}$ possibly comprises RT coexisting phases, not core-shell rhombohedral as observed in other compositions, since a lower $R_{\text {wp }}$ value was obtained by full-pattern refinement with the R-T model (7.46\%) compared with the coreshell rhombohedral model (7.77\%). This is possibly due to the broadening of the R-T phase coexistence region, which occurs at $20^{\circ} \mathrm{C}$ in $3 \mathrm{BNKZ}$, with increasing BNKZ content. Furthermore, the coexistence of rhombohedral and cubic phases $(R-C)$ is observed at $20^{\circ} \mathrm{C}$, whereas core-shell cubic $\left(C_{\text {core }}-C_{\text {shell }}\right)$ was identified at $227^{\circ} \mathrm{C}$ and $350^{\circ} \mathrm{C}$ for $5 B N K Z$, as shown in Figure 6(d).

\subsection{Temperature-dependent dielectric properties}

The phase transformation temperatures in KNNS-BNKZ ceramics were investigated by temperature-dependent dielectric permittivity and loss tangent measurements over the temperature range from $50^{\circ} \mathrm{C}$ to $450^{\circ} \mathrm{C}$, as shown in Figure 9. Note that only two phase transition temperatures, $\mathrm{T}_{\mathrm{O}-\mathrm{T}}$ and $\mathrm{T}_{\mathrm{c}}$, could be observed from the $\varepsilon_{\mathrm{r}}-\mathrm{T}$ plots. It is apparent that $\mathrm{T}_{\mathrm{c}}$ reduces gradually from $\sim 300^{\circ} \mathrm{C}$ to $\sim 200^{\circ} \mathrm{C}$, while $\mathrm{T}_{\mathrm{O}-\mathrm{T}}$ decreases slightly from $\sim 125^{\circ} \mathrm{C}$ to below $50^{\circ} \mathrm{C}$ as the $\mathrm{BNKZ}$ content changes from 
1 OBNKZ to 4BNKZ. Moreover, the change of dielectric permittivity as a function of temperature at both

$2 \mathrm{~T}_{\mathrm{O}-\mathrm{T}}$ and $\mathrm{T}_{\mathrm{C}}$ becomes more diffuse as BNKZ content increases, which correlates well with the SXPD

3 results described in section 3.2 above. However, the orthorhombic phase may not completely disappear for 3BNKZ to 4BNKZ composition as found in the SXPD result, since the presence of subtle change at $\mathrm{T}_{\mathrm{O}-\mathrm{T}}$ for temperature-dependent dielectric permittivity as well as polarisation is still observed as seen in Figure 9 and Figure 12, respectively. The inset plots in Figure 9 show the results for 5BNKZ, which exhibited a diffuse phase transition due to the fine-grained microstructure shown in Figure 1(d). because of its low relative density $(<90 \%)$ as described previously. [31]
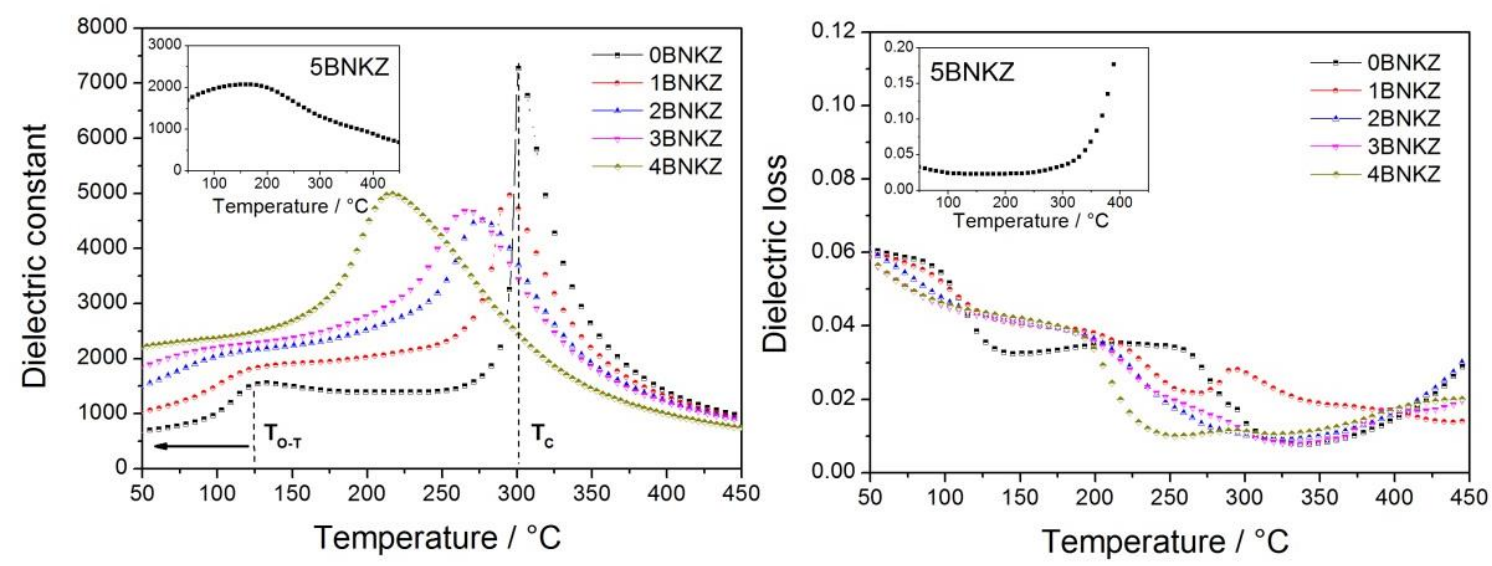

10

11 Figure 9. $\varepsilon_{r}$-Tand tan $\delta$-T plots for KNNS-BNKZceramics, measured at $100 \mathrm{kHz}$, showing the decrease of orthorhombic-tetragonal $\left(T_{0-T}\right)$ and tetragonal-cubic $\left(T_{c}\right)$ phase transition temperatures with increasing BNKZ content. A comparison of the contour maps of the $\{200\}_{p}$ XRD peak profiles, dielectric permittivity and loss tangent in the temperature range from $50^{\circ} \mathrm{C}$ to $200^{\circ} \mathrm{C}$ for $0 \mathrm{BNKZ}$ and $4 \mathrm{BNKZ}$ is presented in Figure 10(a) and (b) respectively, in order to study the relationship between the O-T structural phase transformation and dielectric properties. It was found that the abrupt change of dielectric permittivity for OBNKZ starts at $\sim 100^{\circ} \mathrm{C}$ and reached a peak at $\sim 125^{\circ} \mathrm{C}$, while the crystal structure fully transforms to tetragonal beyond $125^{\circ} \mathrm{C}$. The increase in dielectric permittivity at $\mathrm{T}_{\text {O- }}$ is derived from both intrinsic 
1 (lattice distortion, ionic polarization) and extrinsic (domain wall motion, localised domain switching)

2 contributions. $[48,49]$ In contrast, the $\tan \delta$ values reduced gradually over the same temperature

3 range, indicating that the domain walls are generally less mobile in the tetragonal phase region, as reported by Peng et al.[50] However, the $\mathrm{T}_{\text {O-T }}$ was not observed in this range of temperature in 4BNKZ but the sudden increase of dielectric permittivity was observed from $\sim 150^{\circ} \mathrm{C}$ to $\sim 200^{\circ} \mathrm{C}$ due to approaching the tetragonal-cubic phase transformation at $T_{c}$, as shown in Figure $10(b)$.
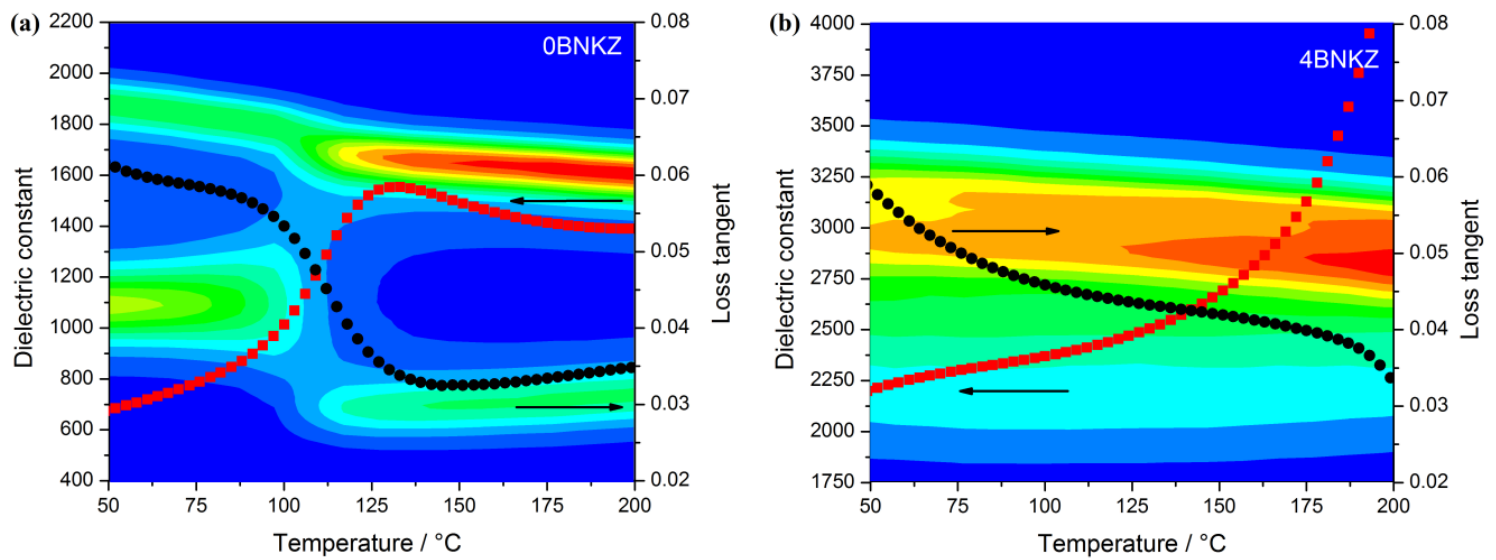

Figure 10. Comparison between diffraction data, represented as contour maps of $\{200\}_{p}$ peak profiles, dielectric permittivity (red squares) and loss tangent (black circles) measured at $100 \mathrm{kHz}$ for (a)OBNKZ and (b)4BNKZ upon heating from 50 to $200{ }^{\circ} \mathrm{C}$.

\subsection{Temperature-dependent ferroelectric properties}

Figure $11(a)$ and (b) illustrate the effect of temperature on the ferroelectric $P$-E hysteresis loops for 1BNKZ and 5BNKZ ceramics respectively, measured at a frequency of $2 \mathrm{~Hz}$ with an electric field amplitude of $4 \mathrm{kV} \mathrm{mm}-1$. The changes in remnant polarisation $\left(P_{r}\right)$ and coercive field $\left(E_{c}\right)$ as a function of temperature from $25^{\circ} \mathrm{C}$ to $150^{\circ} \mathrm{C}$ for all BNKZ-containing compositions are illustrated in Figure $11(c)$ and $(d)$, respectively. It is apparent that $P_{r}$ and $E_{c}$ decrease gradually with increasing temperature. For $1 \mathrm{BNKZ}, \mathrm{P}_{\mathrm{r}}$ decreases from 0.18 to $0.08 \mathrm{C} \mathrm{m}^{-2}(\sim 54 \%)$ as temperature increases to $150^{\circ} \mathrm{C}$, while the percentage of $\mathrm{P}_{\mathrm{r}}$ degradation for $2 \mathrm{BNKZ}$ to $5 \mathrm{BNKZ}$ compositions is lower which implies more thermal stability. Jin [51] suggested that the thermal degradation in $\mathrm{P}_{r}$ and $E_{c}$ is due primarily to 
1 a reduction in spontaneous polarisation within the domains, which are more easilyswitched under an

2 electric field. These effects can be correlated with the reduction in tetragonality (for example), due to

3 the thermally-dependent lattice parameters, as shown in Figure 8.
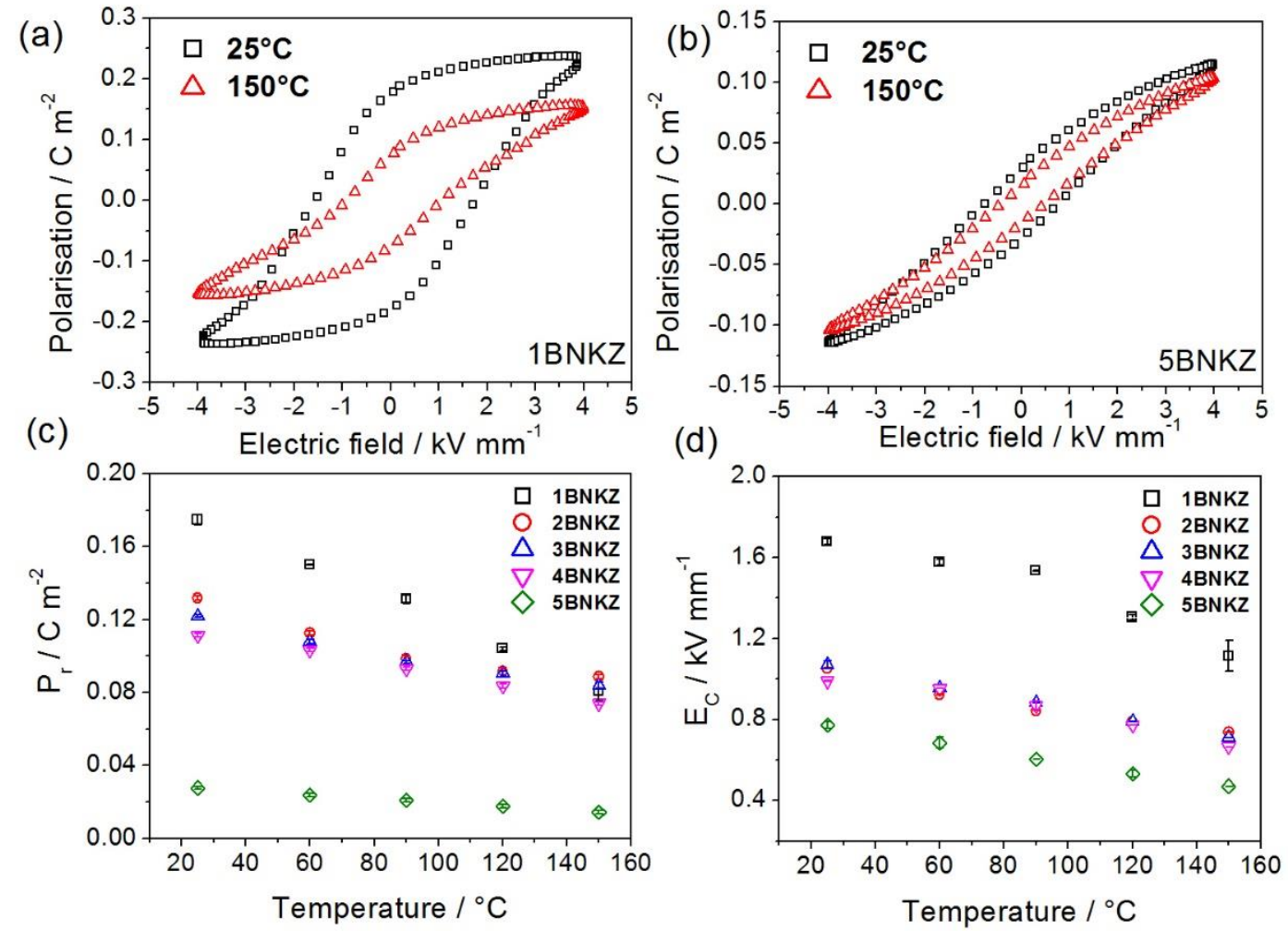

5 Figure 11. Temperature-dependent P-E loops from $25^{\circ} \mathrm{C}$ to $150^{\circ} \mathrm{C}$ for (a)1BNKZ and (b)5BNKZ ceramics

6 with thermaldegradation of (c) remnant polarisation and (d) coercive field for KNNS-BNKZ ceramics.

Although Ochoa [49] reported that the saturation and remnant polarisation values of

$9\left(\mathrm{~K}_{0.44} \mathrm{Na}_{0.52} \mathrm{Li}_{0.04}\right)\left(\mathrm{Nb}_{0.86} \mathrm{Ta}_{0.10} \mathrm{Sb}_{0.06}\right) \mathrm{O}_{3}$ ceramic reach a peak at $\mathrm{T}_{\text {O-T }}$ due to the enhancement of polarisation orientations in the coexisting O-T phases, such an increase of polarisation at $\mathrm{T}_{\text {O-T }}$ was not

11 observed in the present study. However, a marked reduction in $E_{c}$, from $1.53 \mathrm{kV} \mathrm{mm}^{-1}\left(\right.$ at $\left.90^{\circ} \mathrm{C}\right)$ to 1.30

$12 \mathrm{kV} \mathrm{mm}^{-1}$ (at $\left.120^{\circ} \mathrm{C}\right)$, was evidentfor $1 \mathrm{BNKZ}$, as shown in Figure 11(d). According to the results reported

13 in section 3.2, the broadening of the phase transformation ranges was observed with increasing BNKZ

14 content. In otherwords, the 1BNKZ composition, which exhibits the narrowest phase transformation 
1 region, also shows the strongest reduction $\sin \mathrm{P}_{\mathrm{r}}$ and $\mathrm{E}_{\mathrm{c}}$ with increasing temperature. Therefore, it can

2 be assumed that the broadening of phase transformation regions can play a significant role in the

3 improvement of thermal stabilisation of $\mathrm{P}_{\mathrm{r}}$ and $\mathrm{E}_{\mathrm{c}}$ for KNNS-BNKZ ceramics.

4

\subsection{Thermal depolarisation}

The influence of BNKZ content on the depolarisation behaviour of KNNS ceramics was studied

7 in the temperature range between $50^{\circ} \mathrm{C}$ and $300^{\circ} \mathrm{C}$, as shown in Figure 12. For BNT-based ceramics,

8 the depolarisation temperature $\left(T_{d}\right)$ was defined by Anton [52] as the temperature at which the

9 steepest decrease of remnant polarisation occurs as a function of temperature, due to the occurrence

10 of polymorphic phase transformations. In the present results, it was found that there are two

11 depolarisation regions for the $1 \mathrm{BNKZ}$ ceramic; the first occurs at $\sim 110^{\circ} \mathrm{C}$ and the second at $\sim 285^{\circ} \mathrm{C}$,

12 corresponding to the $\mathrm{T}_{\mathrm{O-T}}$ and $\mathrm{T}_{\mathrm{c}}$ values observed in the $\varepsilon_{\mathrm{r}}-\mathrm{T}$ plots (Figure 9). With increasing BNKZ

13 content, gradual reductions in $\mathrm{T}_{\mathrm{C}}$ and $\mathrm{T}_{\mathrm{O}-\mathrm{T}}$, similar to those observed by the SXPD and dielectric measurements, are also confirmed by the depolarisation study.

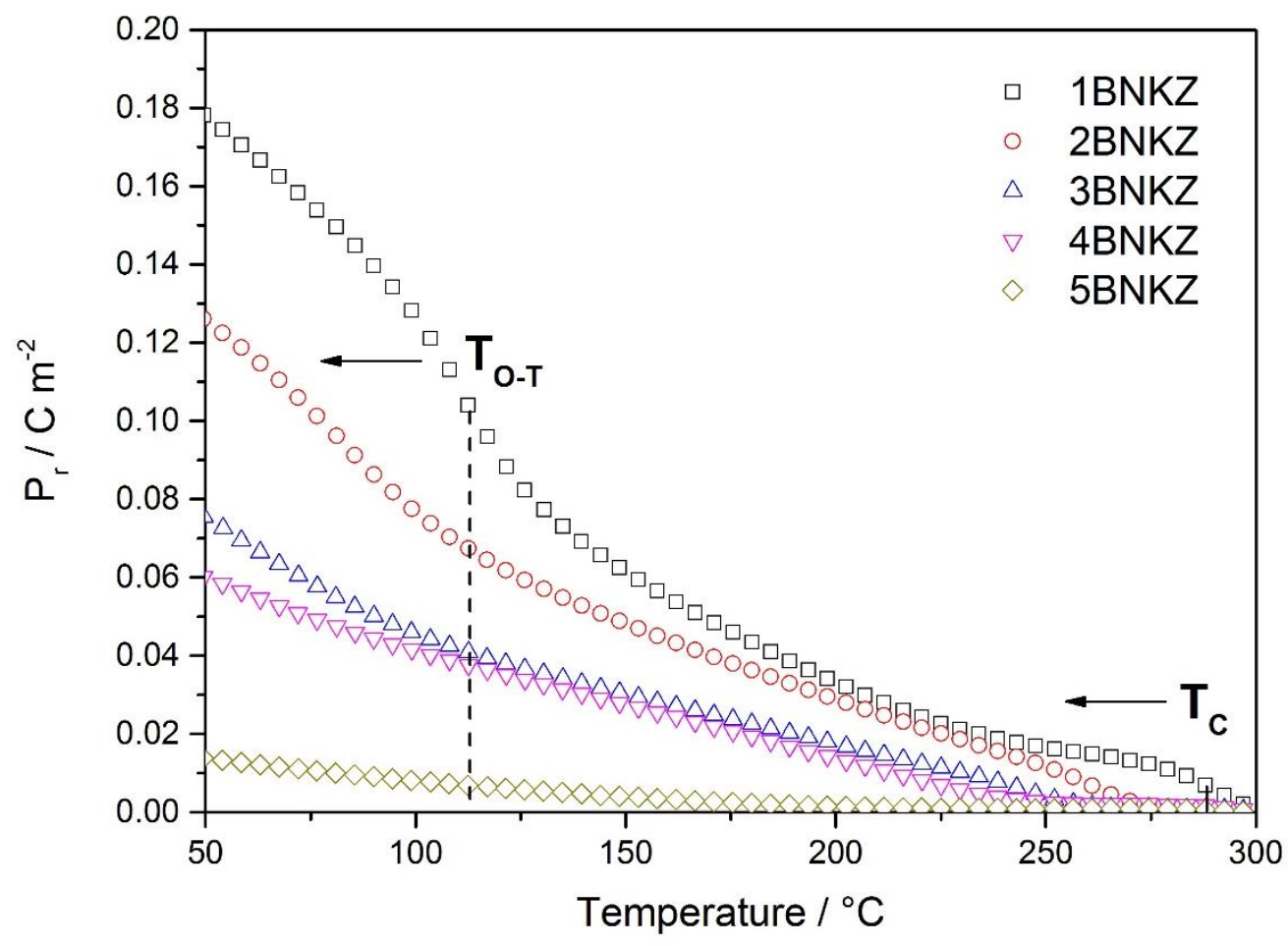


1 Figure 12. Thermal depolarisation for $1 B N K Z$ to $5 B N K Z$ ceramics showing the decrease of 2 depolarisation temperature with increasing BNKZ content.

3

4 Conclusions

Investigations on thermally-induced phase transformations and functional properties of

6 KNNS-BNKZ ceramics were presented in this work. The introduction of BNKZ into KNNS solid solutions

7 leads to the formation of core-shell microstructures due to chemical heterogeneity, which has a strong

8 influence on crystal structure. This indicates that the enhancement of piezoelectric properties for

9 KNNS-BNKZ ceramic is possibly due to the contributions of both intrinsic and extrinsic factors.

10 Temperature-dependent SXPD measurements were employed to clarify the effect of BNKZ on the

11 polymorphic phase transformations. Persistent low-angle shoulders, which were observed in all

12 diffraction peak profiles even after transformation to the cubic phase, are attributed to differences in

13 potassium content between core and shell regions. As a result, the coexistence of core-shell

14 rhombohedral, orthorhombic, tetragonal and cubic phases was identified for different temperatures

15 and compositions. Furthermore, the shifting of $\mathrm{T}_{\mathrm{O}-\mathrm{T}}$ and $\mathrm{T}_{\mathrm{R}-\mathrm{O}}$ toward room temperature, due to the

16 addition of BNKZ and Sb into KNN ceramics, as mentioned in previous literature[30], was also

17 confirmed in the present study by high resolution SXPD, leading to the occurrence of O-T or R-T mixed

18 phases at room temperature with increasing BNKZ content. Additionally, reductions in $\mathrm{T}_{\mathrm{O}-\mathrm{T}}$ and $\mathrm{T}_{\mathrm{c}}$ with

19 increasing BNKZ content were verified by measurements of the temperature-dependent dielectric

20 properties and thermal depolarisation behaviour. Temperature-dependent ferroelectric measurements demonstrated thermal degradation in $\mathrm{P}_{r}$ and $\mathrm{E}_{c}$ values, but improvement of themal stability due to broadening of the phase transformation regions with increasing BNKZ content in KNNS ceramics. 


\section{Acknowledgements}

We would like to thank Diamond Light Source for access to beamline I11 (proposal number

EE13116) that contributed to the results presented here. Also, JT thanks Thammasat University for financial support in the form of a PhD scholarship at the University of Manchester.

\section{References}

1. Rodel J, Jo W, Seifert KTP, AntonEM, Granzow T, Damjanovic D. Perspective on the Devel opment of Lead-free Piezoceramics. J Am Ceram Soc. 2009;92:1153-77.

2. Panda PK, Sahoo B. PZT to Lead Free Piezo Ceramics: A Review. Ferroelectrics. 2015;474:128-43.

3. Guo R, Cross LE, Park SE, Noheda B, Cox DE, Shirane G. Origin of the High Piezoelectric Response in $\mathrm{PbZr}_{1-\mathrm{x}} \mathrm{Ti}_{x} \mathrm{O}_{3}$. Physical Review Letters. 2000;84:5423-6.

4. Ringgaard E, Wurlitzer T. Lead-free piezoceramics based on alkali niobates. Journal of the European Ceramic Society. 2005;25:2701-6.

5. Rodel J, Webber KG, Dittmer R, Jo W, Kimura M, Damjanovic D. Transferring lead-free piezoelectric ceramics into application. Journal of the European Ceramic Society. 2015;35:165981.

6. Takenaka T. Lead-Free Piezoelectric Ceramics. San Diego: Elsevier Academic Press Inc; 2013.

7. Rigoberto L-J, Federico G, María-Elena V-C. Lead-Free Ferroelectric Ceramics with Perovskite Structure: InTech; 2011.

8. Shrout TR, Zhang SJ. Lead-free piezoelectric ceramics: Alternatives for PZT? Journal of Electroceramics. 2007;19:111-24.

9. Li JF, Wang K, Zhu FY, Cheng LQ, Yao FZ. (K, Na) $\mathrm{NbO}_{3}$-Based Lead-Free Piezoceramics: Fundamental Aspects, Processing Technologies, and Remaining Challenges. J Am Ceram Soc. 2013;96:3677-96.

10. Lidjici $H$, Lagoun $B$, Berrahal $M$, Rguitti $M$, Hentatti MA, Khemakhem H. XRD, Raman and electrical studies on the (1-x) $\left(\mathrm{Na}_{0.5} \mathrm{Bi}_{0.5}\right) \mathrm{TiO}_{3}-\mathrm{xBaTiO}$ lead free ceramics. J Alloy Compd. 2015;618:643-8.

11. Moosavi A, Bahrevar MA, Aghaei AR, Ramos P, Alguero M, Amorin H. High-field electromechanical response of $\mathrm{Bi}_{0.5} \mathrm{Na}_{0.5} \mathrm{TiO}_{3}-\mathrm{Bi}_{0.5} \mathrm{~K}_{0.5} \mathrm{TiO}_{3}$ across its morphotropic phase boundary. J Phys D-Appl Phys. 2014;47.

12. Otoničar M, Škapin SD, Spreitzer M, Suvorov D. Compositional range and electrical properties of the morphotropic phase boundary in the $\mathrm{Na}_{0.5} \mathrm{Bi}_{0.5} \mathrm{TiO}_{3}-\mathrm{K}_{0.5} \mathrm{Bi}_{0.5} \mathrm{TiO}_{3}$ system. Journal of the European Ceramic Society. 2010;30:971-9.

13. Atsushi S, Tatsuya $\mathrm{C}$, Youichi M, Etsuo O. Dielectric and Piezoelectric Properties of $\left(\mathrm{Bi}_{0.5} \mathrm{Na}_{0.5}\right) \mathrm{TiO}_{3}-$ $\left(\mathrm{Bi}_{0.5} \mathrm{~K}_{0.5}\right) \mathrm{TiO}_{3}$ Systems. Japanese Journal of Applied Physics. 1999;38:5564.

14. Pal V, Thakur OP, Dwivedi RK. Investigation of MPB region in lead free BLNT-BCT system through XRD and Raman spectroscopy. J Phys D-Appl Phys. 2015;48.

15. Pan Z, Wang Q, Chen J, Liu C, Fan LL, Liu L, Fang L, Xing XR. Enhanced Piezoelectric Properties of Tetragonal $\left(\mathrm{Bi}_{1 / 2} \mathrm{~K}_{1 / 2}\right) \mathrm{TiO}_{3}$ Lead-Free Ceramics by Substitution of Pure Bi-Based Bi $\left(\mathrm{Mg}_{2 / 3} \mathrm{Nb}_{1 / 3}\right) \mathrm{O}_{3}$. J Am Ceram Soc. 2015;98:104-8.

16. Martin-Arias L, Castro A, Alguero M. Ferroelectric phasesand relaxor states in the novel lead-free (1-x) $\mathrm{Bi}_{1 / 2} \mathrm{~K}_{1 / 2} \mathrm{TiO}_{3}-\mathrm{xBiScO}{ }_{3}$ system $(0<=\mathrm{x}<=0.3$ ). J Mater Sci. 2012;47:3729-40. 
17. Morozov Ml, Einarsrud MA, Grande T. Polarization and strain response in $\mathrm{Bi}_{0.5} \mathrm{~K}_{0.5} \mathrm{TiO}_{3}-\mathrm{BiFeO}_{3}$ ceramics. Applied Physics Letters. 2012;101.

18. Cheng RF, Xu ZJ, Chu RQ, Hao JG, Du J, Li GR. Structure and electrical properties of $\mathrm{Bi}_{1 / 2} \mathrm{Na}_{1 / 2} \mathrm{TiO}_{3}$ based lead-free piezoelectric ceramics. RSC Adv. 2015;5:41646-52.

19. Cheng RF, Xu ZJ, Chu RQ, Hao JG, Du J, Ji WB, Li GR. Large piezoelectric effect in $\mathrm{Bi}_{1 / 2} \mathrm{Na}_{1 / 2} \mathrm{TiO}_{3^{-}}$ based lead-free piezoceramics. Ceram Int. 2015;41:8119-27.

20. Zhou CR, Liu XY, Li WZ, Yuan CL. Dielectric and piezoelectric properties of $\mathrm{Bi}_{0.5} \mathrm{Na}_{0.5} \mathrm{TiO}_{3^{-}}$ $\mathrm{Bi}_{0.5} \mathrm{~K}_{0.5} \mathrm{TiO}_{3}-\mathrm{BiCrO}_{3}$ lead-free piezoelectric ceramics. J Alloy Compd. 2009;478:381-5.

21. Li XH, Jiang M, Liu J, Zhu JL, Zhu XH, Li LH, Zhou Y, Zhu JG, Xiao DQ. Phase transitionsand electrical properties of $(1-x)\left(\mathrm{K}_{0.5} \mathrm{Na}_{0.5}\right) \mathrm{NbO}_{3}-\mathrm{xBiScO}_{3}$ lead-free piezoelectric ceramics with a $\mathrm{CuO}$ sintering aid. Phys Status Solidi A-Appl Mat. 2009;206:2622-6.

22. Wu J, Xiao D, Wang $\mathrm{Y}, \mathrm{Wu}$ W, Zhang B, Zhu J. Improved te mperature stability of $\mathrm{CaTiO}_{3}$-modified $\left[\left(\mathrm{K}_{0.5} \mathrm{Na}_{0.5}\right)_{0.96} \mathrm{Li}_{0.04}\right]\left(\mathrm{Nb}_{0.91} \mathrm{Sb}_{0.05} \mathrm{Ta}_{0.04}\right) \mathrm{O}_{3}$ lead-free piezoelectric ceramics. Journal of Applied Physics. 2008;104:024102.

23. Lin D, Kwok KW, Chan HLW. Microstructure, dielectric and piezoelectric properties of $\left(\mathrm{K}_{0.5} \mathrm{Na}_{0.5}\right) \mathrm{NbO}_{3}-\mathrm{Ba}\left(\mathrm{Ti}_{0.95} \mathrm{Zr}_{0.05}\right) \mathrm{O}_{3}$ lead-free ceramics with $\mathrm{CuO}$ sintering aid. Appl Phys A-Mater Sci Process. 2007;88:359-63.

24. Zhang S, Xia R, Shrout TR, Zang G, Wang J. Piezoelectric properties in perovskite $0.948\left(\mathrm{~K}_{0.5} \mathrm{Na}_{0.5}\right) \mathrm{NbO}_{3}-0.052 \mathrm{LiSbO}_{3}$ lead-free ceramics. Journal of Applied Physics. 2006;100:104108.

25. Park H-Y, Ahn C-W, Song H-C, Lee J-H, Nahm S, Uchino K, Lee H-G, Lee H-J. Microstructure and piezoelectric properties of $0.95\left(\mathrm{Na}_{0.5} \mathrm{~K}_{0.5}\right) \mathrm{NbO}_{3}-0.05 \mathrm{BaTiO}_{3}$ ceramics. Applied Physics Letters. 2006;89:062906.

26. Gong YQ, Yang G, Li XJ, Gong L, Li L, Peng JF, Zheng XJ. Piezoelectric properties and aging mechanism of $\mathrm{K}_{0.5} \mathrm{Na}_{0.5} \mathrm{Nb}_{(1-y)} \mathrm{Sb}_{\mathrm{y}} \mathrm{O}_{3}$ piezoceramics prepared by low temperature solvothermal method. J Mater Sci-Mater Electron. 2012;23:1910-5.

27. Rubio-Marcos F, López-Juárez R, Rojas-Hernandez RE, del Campo A, Razo-Pérez N, Fernandez JF. Lead-Free Piezoceramics: Revealing the Role of the Rhombohedral-Tetragonal Phase Coexistence in Enhancement of the Piezoelectric Properties. ACS Applied Materials \& Interfaces. 2015;7:23080-8.

28. Rubio-Marcos F, Fernandez JF, Ochoa DA, García JE, Rojas-Hernandez RE, Castro M, Ramajo L. Understanding the piezoelectric properties in potassium-sodium niobate-based lead-free piezoceramics: Interrelationship between intrinsicand extrinsic factors. Journal of the European Ceramic Society. 2017;37:3501-9.

29. Wang K, Yao FZ, Jo W, Gobeljic D, Shvartsman VV, Lupascu DC, Li JF, Rodel J. TemperatureInsensitive $(\mathrm{K}, \mathrm{Na}) \mathrm{NbO}_{3}$-Based Lead-Free Piezoactuator Ceramics. Adv Funct Mater. 2013;23:4079-86.

30. Wang XP, Wu JG, Xiao DQ, Zhu JG, Cheng XJ, Zheng T, Zhang BY, Lou XJ, Wang XJ. Giant Piezoelectricity in Potassium-Sodium Niobate Lead-Free Ceramics. J Am Chem Soc. 2014;136:2905-10.

31. Tangsritrakul J, Hall DA. Structural and functional characterisation of KNNS-BNKZ lead-free piezoceramics. Advances in Applied Ceramics. 2018;117:42-8.

32. Bomlai $P$, Wichianrat $P$, Muensit $S$, Milne SJ. Effect of calcination conditions and excess alkali carbonate on the phase formation and particle morphology of $\mathrm{Na}_{0.5} \mathrm{~K}_{0.5} \mathrm{NbO}_{3}$ powders. J Am Ceram Soc. 2007;90:1650-5.

33. Mendelson MI. Average grain size in polycrystalline ceramics J Am Ceram Soc. 1969;52:443.

34. Stewart M, Cain MG, Hall DA. Ferroelectric Hysteresis Measurement \& Analysis. Teddington: National Physical Laboratory, 1999.

35. Thompson SP, Parker JE, Potter J, Hill TP, Birt A, Cobb TM, Yuan F, Tang CC. Beamline I11 at Diamond: A new instrument for high resolution powder diffraction. Review of Scientific Instruments. 2009;80:075107. 
36. Coelho AA. TOPAS and TOPAS-Academic: an optimization program integrating computer algebra and crystallographic objects written in C++. Journal of Applied Crystallography. 2018;51:210-8.

37. Liu $\mathrm{ZY}$, Fan $\mathrm{HQ}$, $\mathrm{Li} \mathrm{MM}$. High temperature stable dielectric properties of $\left(\mathrm{K}_{0.5} \mathrm{Na}_{0.5}\right)_{(0.985)} \mathrm{Bi}_{0.015} \mathrm{Nb}_{0.99} \mathrm{Cu}_{0.01} \mathrm{O}_{3}$ ceramics with core-shell microstructures. J Mater Chem $\mathrm{C}$. 2015;3:5851-8.

38. Acosta M, Schmitt LA, Molina-Luna L, Scherrer MC, Brilz M, Webber KG, Deluca M, Kleebe H-J, Rödel J, Donner W. Core-Shell Lead-Free Piezoelectric Ceramics: Current Status and Advanced Characterization of the $\mathrm{Bi}_{1 / 2} \mathrm{Na}_{1 / 2} \mathrm{TiO}_{3}-\mathrm{SrTiO}_{3}$ System. J Am Ceram Soc. 2015;98:3405-22.

39. Xing J, Tan Z, Jiang L, Chen $Q$, Wu J, Zhang W, Xiao D, Zhu J. Phase structure and piezoelectric properties of $(1-\mathrm{x}) \mathrm{K}_{0.48} \mathrm{Na}_{0.52} \mathrm{Nb}_{0.95} \mathrm{Sb}_{0.05} \mathrm{O}_{3}-\mathrm{x}\left(\mathrm{Bi}_{0.5} \mathrm{Na}_{0.5}\right)_{0.9}\left(\mathrm{Li}_{0.5} \mathrm{Ce}_{0.5}\right)_{0.1} \mathrm{ZrO}_{3}$ lead-free piezoelectric ceramics. Journal of Applied Physics. 2016;119:034101.

40. Wang Y, Damjanovic D, Klein N, Hollenstein E, Setter N. Compositional Inhomogeneity in Li - and Ta-Modified ( $\mathrm{K}, \mathrm{Na}) \mathrm{NbO}_{3}$ Ceramics. J Am Ceram Soc. 2007;90:3485-9.

41. Zhen Y, Li J-F. Abnormal Grain Growth and New Core-Shell Structure in (K,Na) $\mathrm{NbO}_{3}$-Based LeadFree Piezoelectric Ceramics. J Am Ceram Soc. 2007;90:3496-502.

42. Choi SY, Jeong SJ, Lee DS, Kim MS, Lee JS, Cho JH, Kim BI, Ikuhara Y. Gigantic Electrostrain in Duplex Structured Alkaline Niobates. Chem Mat. 2012;24:3363-9.

43. Zhou M, Lu XM, Yang DY, He J, Huang FZ, Mei F, Ren XM, Xu XY, Li Y, Zhu JS. Induced core-shell structure and the electric properties of $\left(\mathrm{K}_{0.48} \mathrm{Na}_{0.52}\right)_{0.95} \mathrm{Li}_{0.05} \mathrm{Nb}_{0.95} \mathrm{Sb}_{0.05} \mathrm{O}_{3}$ ceramics. Phys Chem Chem Phys. 2017;19:1868-74.

44. Thong H-C, Zhao C, Zhu Z-X, Chen X, Li J-F, Wang K. The impact of chemical heterogeneity in leadfree $(\mathrm{K}, \mathrm{Na}) \mathrm{NbO} 3$ piezoelectric perovskite: Ferroelectric phase coexistence. Acta Mate rialia. 2019;166:551-9.

45. Malic B, Bernard J, Bencan A, Kosec M. Influence of zirconia addition on the microstructure of $\mathrm{K}_{0.5} \mathrm{Na}_{0.5} \mathrm{NbO}_{3}$ ceramics. Journal of the European Ceramic Society. 2008;28:1191-6.

46. Zuo R, Fu J, Lv D, Liu Y. Antimony Tuned Rhombohedral-Orthorhombic Phase Transition and Enhanced Piezoelectric Properties in Sodium Potassium Niobate.J Am Ceram Soc. 2010;93:27837.

47. Tellier J, Malic B, Dkhil B, Jenko D, Cilensek J, Kosec M. Crystal structure and phase transitions of sodium potassium niobate perovskites. Solid State Sciences. 2009;11:320-4.

48. Damjanovic D. A morphotropic phase boundary system based on polarization rotation and polarization extension. Applied Physics Letters. 2010;97:062906.

49. Ochoa DA, Esteves G, Jones JL, Rubio-Marcos F, Fernández JF, García JE. Extrinsic response enhancement at the polymorphic phase boundary in piezoelectric materials. Appl Phys Lett. 2016;108:142901.

50. Peng B, Yue Z, Li L. Evaluation of domain wall motion during polymorphic phase transition in (K, $\mathrm{Na}$ ) NbO3-based piezoelectric ceramics by nonlinear response measurements. Journal of Applied Physics. 2011;109:054107.

51. Jin L, Li F, Zhang SJ. Decoding the Fingerprint of Ferroelectric Loops: Comprehension of the Material Properties and Structures. J Am Ceram Soc. 2014;97:1-27.

52. Anton E-M, Jo W, Damjanovic D, Rödel J. Determination of depolarization temperature of $\left(\mathrm{Bi}_{1 / 2} \mathrm{Na}_{1 / 2}\right) \mathrm{TiO}_{3}$-based lead-free piezoceramics. Journal of Applied Physics. 2011;110:094108. 